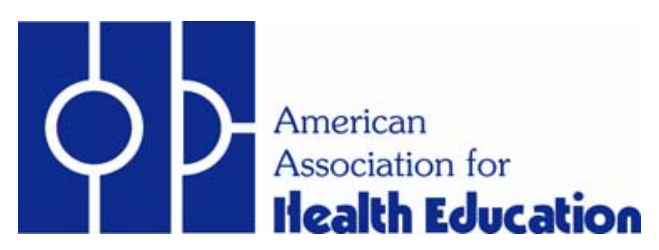

\title{
AAHE At-A-Glance
}

Volume 2, Issue 3, September 1, 2004

\section{Hello CJHP Readers!}

In this issue of AAHE At-A-Glance, I have included updates on the following:

1. 2004 AAHE Faculty Development Institute

a. Registration Form

b. Registration Form (complete this form in MS Word and then print)

2. Tomita Receives HEDIR Technology Award

3. AAHE Faculty Intern, Dr. Jane Elphingstone to work with AAHE

4. Dr. Mirushe Emini of the HOPE Fellows Program of the National Albanian American Council visits AAHE

5. AAHE Receives Funding from $C D C$

Thank you for reading.

For more information about AAHE, please go to this website -http://WWW . aahperd.org/aahe

Susan Giarratano Russell, EdD, MSPH, CHES

AAHE Contributing Editor

Glendale, California 


\section{AAHE FACULTY DEVELOPMENT INSTITUTE}

October 1-3, 2004

National Conference Center

Lansdowne, Virginia

www.aahperd.org/aahe

(703) 476-3437

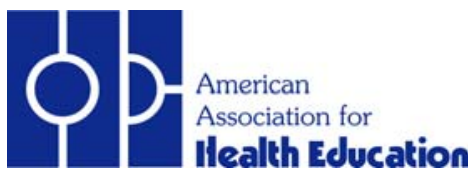




\section{AAHE Faculty Development Institute October 1-3, 2004}

\section{National Conference Center 18980 Upper Belmont Place Lansdowne, VA 20176}

Registration Fee: \$100/workshop

Lodging Fee: \$145/day (includes lodging, 3 meals per day, snacks, access to recreational facilities, gym, and tennis courts. The National Conference Center is located approximately 12 miles from Washington Dulles International Airport.

\section{Who Should Attend?}

- Health Education Faculty

- Teacher Preparation Faculty

- College/University Peer Health Education Coordinators

- State Education Agency Personnel

\section{Institute Highlights}

This institute will provide 4 workshops that will focus on faculty and staff development in the following areas:

\section{- Standards-based Health Education \& Performance Assessment Workshop}

\section{Friday, October 1, 2004, 8:00 am - 5:00 pm}

The workshop will provide health education teacher preparation faculty with the knowledge and skills needed to professionally prepare teachers to effectively use the National Health Education Standards and performance-based assessment to promote health literacy. The participants will receive a manual on standards-based health education \& performance assessment entitled "Health Literacy: Teaching HIV Prevention through Standards-based Health Education \& Performance Assessment," and a CDROM which contains PowerPoint presentations, handouts, and overheads.

\section{- AAHE/NCATE University Preparation Workshop}

\section{Saturday, October 2, 2004, 8:00 am - 5:00 pm}

This workshop will provide guidance to institutions of higher education in preparing a health education program report for AAHE/NCATE review. In addition, the workshop participants will receive training and handouts on the new web-based program report submission and review. For a fee of $\$ 100$, institutions may send up to 2 representatives; each additional attendee will be $\$ 50$. Each institution will receive one copy of 2001 Guidelines for AAHE/NCATE Review of Initial Level Programs for Health Education Teacher Preparation, and CD-ROM containing the guidelines document.

\section{- Peer Health Education Coordinators Workshop}

\section{Friday, October 1, 2004, 8:00 am - 5:00 pm}

This workshop is designed to provide assistance and comprehensive resources for colleges/universities to develop or enhance a peer health education program. The workshop will help the participants to develop the skills to effectively plan, execute, and evaluate a quality peer health education program. The workshop participants will receive a peer health education coordinators 
manual, a CD-ROM that contains checklists, resources, sample forms and sample activities, and a one-year subscription to a subscription-based peer health education website.

- $\quad$ Research \& Evaluation Workshop

Saturday, October 2, 2004, 8:00 am - 5:00 pm \&

Sunday, October 3, 2004, 8:00 am - 11:30 am

This workshop is designed to enhance faculty and staff qualitative research skills, emphasis will be placed on focus groups.

Continuing education credit, including CHES credit, will be offered. The Institute is limited to the first 40 registrants. For more information, please contact Deborah Fortune at 1-800-213-7193, ext. 439.

Or visit our website: www.aahperd.org/aahe 


\section{Registration Form}

\section{AAHE Faculty Development Institute National Conference Center \\ Lansdowne, Virginia \\ October 1-3, 2004}

Click here for this form in MS Word

Name

Title

Organization

Address

City State Zip

Phone Fax

Email

Dates you need lodging, check all that apply:

a Thursday

a Friday

a Saturday

I I do not need lodging

I plan to attend:

a Standards \& Performance Assessment Workshop - \$100

a AAHE/NCATE University Preparation Workshop - $\$ 100$

口 Peer Health Education Coordinators Workshop - \$100

口 Research \& Evaluation Workshop - \$100

Total Remittance

\section{Method of Payment}

- Check/Purchase Order (enclosed with registration form)

a VISA

- MasterCard

口 American Express

Credit Card \# Exp. Date

Signature

Please make checks payable to: AAHPERD/AAHE, 1900 Association Drive, Reston, VA 20191 


\section{Tomita Receives HEDIR Technology Award}

Mark Tomita, PhD, RN, CHES, Associate Professor of Health Education at California State University, Chico, has been selected as the 2004 AAHE/HEDIR Technology Recipient. The award honors health educators who have made a significant contribution to the profession of health education in the use of technology. Dr. Tomita will receive his award at an awards breakfast this fall in Washington, DC.

Dr. Tomita has had a long history of involvement in technology. While earning his PhD at New York University, he worked with Dr. Alyson Taub in the creation of the Health Education Professional Resources (HEPR) web site. Under the auspices of Dr. Taub, the HEPR served as an electronic resource for health educators in jobs, national news, and organizational information.

Since arriving at Chico, Dr. Tomita has created the Californian Journal of Health Promotion (http://www.cjhp.org), an on-line peer reviewed journal. In addition, he has authored one book and a number of journal articles, specifically focusing on helping the practitioner using technology in delivering health education programs.

The HEDIR Technology Award, started in 1997, is to recognize a health educator, or a group, who has made outstanding contributions to the profession of health education through technology or who has transformed the profession of health education. The list of awards winners is a virtual Who's Who in Health Education. The recipients have been 1997 Robert Gold, 1998 Billie Lindsey, 1999 Judy Baker, and Vic Strecher, 2000 Alyson Taub, 2001 James Eddy, 2002 Michael Pejsach and Michaela Conley, 2003 Elaine Auld, Don Chaney, and Min Qi Wang.

The HEDIR Technology Award was the brainchild of Dr. Mark Kittleson, Southern Illinois University. Discouraged by the lack of support for technological advances by the profession, in early 1997 Dr. Kittleson approached Jones and Bartlett Publishers to see if they would be willing to sponsor the award. From 1997 until 2002, Jones and Bartlett sponsored the HEDIR luncheon, held in conjunction with the American Public Health Association meeting in the late fall. In 2003, McGraw-Hill Publishers agreed to take over the sponsorship of the award. The 2003 event, also held during APHA in San Francisco, was slightly different in that this year's event was held as a breakfast award.

In 2001, AAHE arranged with the HEDIR to serve as the exclusive sponsor of the HEDIR. The collaboration of the largest health education organization, and the most well-known and popular discussion group (the HEDIR) allows for an even greater expansion of the role of technology in today's profession. In 2002, the Board of Directors approved the plan for AAHE to co-sponsor the HEDIR Technology Award. This co-sponsorship includes the promotion of the event, promotion of the main sponsor of the event (McGraw-Hill), and the use of the AAHE Technology Task Force to assist in the selection process. The AAHE/HEDIR sponsorship agreement goes until 2008.

The HEDIR currently has over 1,500 subscribers. In addition, the HEDIR maintains an up-to-date registry of participants. Besides email, the database contains position, employment, address, fax, phone, and areas of interest. One can go to http://www.hedir.org/directory to search for HEDIR participants. All HEDIR messages have been archived since the inception of the HEDIR (1994). One can go to http://www.hedir.org, click the archived menu. Most recently, the HEDIR has a search engine to of all messages.

$\underline{\text { Back to Top }}$ 


\section{AAHE Faculty Intern Arrives}

The American Association for Health Education (AAHE) is pleased to announce that Dr. Jane Elphingstone, Professor of Health Education at the University of Central Arkansas, will be working with AAHE this fall as an AAHE Professional Intern. Dr. Elphingstone will be on sabbatical leave and during her sabbatical she will be working with on several projects related to the Health Education and Promotion Network at http://www.HEPNetwork.com.

Her dual roles will be to: 1) serve as a course coordinator for a new HEPNetwork course on Alcohol, Tobacco, and other Drugs; and 2) assist AAHE with the marketing and promotion of the HEPNetwork. She may be contacted at AAHE through December 2004.

\section{Dr. Mirushe Emini, Fellow HOPE Fellows Program National Albanian American Council}

\section{Visits AAHE from Kosovo}

Mirushe Emini, a physician from the emerging country of Kosovo has spent 6 weeks at the American Association for Health Education this summer as a participant in the HOPE Fellows Program of the National Albanian American Council. The program is funded by USAID and brings small groups of professional women from Kosovo to the United States for professional leadership development opportunities. Dr. Emini is the Chief of Health Education and Prevention Section for Youth within the Ministry of Youth, Culture, and Sport. She has been very active during her short stay in the U.S. on two important projects.

1. A comparison analysis between the youth health education and prevention system in the USA and Kosovo, and identification of the best practices with relevance for youth policies in her country.

2. Establishment of a private specialized publishing house for medicine and health.

While at AAHE, Dr. Emini had an opportunity to meet with a wide variety of professionals working with NGOs but even more importantly with government staff at the local, state, and federal levels. She has developed a plan of action for each of her extensive projects, which will be carried out in Kosovo during the next several years.

The AAHE staff has enjoyed the opportunity to work with Dr. Emini and to learn so much more about the lives of people in Kosovo. We will miss her participation at the AAHE office; however, we know she will be very glad to get home to her husband, 12-year-old son, and 2-year-old daughter.

$\underline{\text { Back to Top }}$ 


\section{AAHE Receives Funding from CDC}

The American Association for Health Education is pleased to announce funding for a two-year cooperative agreement with the Centers for Disease Control and Prevention, Division of Adolescent and School Health, to strengthen teacher preparation programs in the area of HIV prevention education for school-age youth. The project will provide professional development opportunities for health education faculty, state education agencies personnel, and faculty at Historically Black Colleges and Universities and Hispanic Serving Institutions.

For more information, please contact Deborah A. Fortune, Project Director, at (703) 476-3439.

\section{Back to Top}

